\title{
Satisfaction with Waiting Time and Associated Factors among Outpatients at Nekemte Referral Hospital, Western Ethiopia
}

\author{
Edosa Tesfaye Geta ${ }^{1, *}$, Alemu Mekonnen Edessa ${ }^{2}$ \\ ${ }^{1}$ Department of Health Economics, Management and Policy, Faculty of Public Health, Institute of Health, Jimma University, Oromia, \\ Ethiopia \\ ${ }^{2}$ Gobu Sayo District Health Office, East Wollega Zonal Health Department, Oromia, Ethiopia
}

Email address:

edotesfa@yahoo.com (E. T. Geta)

${ }^{*}$ Corresponding author

\section{To cite this article:}

Edosa Tesfaye Geta, Alemu Mekonnen Edessa. Satisfaction with Waiting Time and Associated Factors among Outpatients at Nekemte Referral Hospital, Western Ethiopia. Rehabilitation Science. Vol. 5, No. 2, 2020, pp. 18-25. doi: 10.11648/j.rs.20200502.12

Received: July 26, 2019; Accepted: September 21, 2019; Published: September 21, 2020

\begin{abstract}
Patients have explicit needs for health care when they visit health facilities and their satisfaction embodies the patients' perceived needs and expectations and they use waiting time as a decisive factor in choosing a health service provider. Hence, the aim of this study was to assess patient satisfaction with waiting time among outpatients and associated factors at Nekemte referral hospital. The study was conducted at Nekemte Referral hospital in Ethiopia. A cross-sectional study design was used to collect data between May 01 and 30, 2016. A 420 samples size was determined using a single population proportion formula. Data entry and analysis were done using SPSS version 20. Descriptive statistics, univariate and multivariable logistic regression were performed. From a total of 420 interviewed participants, 387 of them responded to the interview making $92.2 \%$ response rates. The majority of the participants were male $248(64.1 \%)$ and from urban area 270 $(69.8 \%)$. The overall satisfaction of outpatients with waiting time was $57.1 \%$ and the factors significantly associted with satisfaction toward waiting time to receive health care at outpatient departments of the hospital were waiting time to get registration, waits for visiting physician, waits for laboratory services, waits for drugs, and waits for payment. The overall outpatient satisfaction with waiting time to receive health services at outpatient departments of Nekemte referral hospital was relatively low compared to other many study findings and we recommend the hospital to reduce the waiting time to $\leq 30$ minutes for health services at each outpatient department to increases outpatient satisfaction with waiting time.
\end{abstract}

Keywords: Outpatients, Waiting Time, Patient Satisfaction, Nekemte Referral Hospital, Ethiopia

\section{Introduction}

Patients have explicit needs for health care when they visit any health facility. However, inadequate response to their needs or expectations could result in dissatisfaction to health care services and satisfaction embodies the patients' perceived needs and expectations from the health system [1, $2]$.

The concept of patient satisfaction to health services is widely used to assess the quality of health services and it can be influenced by the hospital structure, appropriateness and timeliness of the service, and length of stay in the hospital
[3].

Nowadays, patients use waiting time as a decisive factor in choosing a health service provider. Therefore, the idle time of both patients and health care providers must be considered in health care provision and utilization [4].

There are no standard or universally accepted definitions of waiting times for a broad range of health services [5]. However, the waiting time can be defined as the time required just after patient's arrival at the outpatient department of the health facility to meet his needs and it is the total time elapsed in circulating the patient from one room to another room of the outpatient department of the health facility. These include the time spent for collecting the 
treatment ticket, for attending the physician, for submission of samples for investigations and for collecting medicines including receiving instructions for their use [6].

Evaluating patient satisfaction at different departments of the health facilities is very important for the provision of health care and the outpatient department (OPD) of the hospital is defined as the hospital departments where patients received diagnosis and or treatment but did not stay overnight. The OPD in any hospital considered to be a shop window of the hospital and there are various problems faced by the patients in the outpatient department of the hospital, such as overcrowding, delay in consultation, lack of proper guidance which leads the patients to be dissatisfied to the health services $[4,7]$.

Longer waiting times are negatively associated with clinical provider scores of patient satisfaction and any healthcare institutions are confronted with long waiting times, delays, and queues of patients $[8,9]$.

In line with this, there is a gap of study on investigation of a diverse set of variables to identify important factors influencing outpatient satisfaction with waiting time in hospital. Hence, the study aimed to assess the patients' satisfaction with waiting time and associated factors among outpatients at referral hospital.

\section{Materials and Methods}

\subsection{Study Setting}

The study was conducted at Nekemte referral hospital between May 01, to 30, 2016. Nekemte referral hospital is located in Nekemte town, East Wollega zone, Oromia National Regional State, Ethiopia which is located 330 kilometers from Addis Ababa the capital city of the country. The hospital catchment population was estimated to be 2028680 and it provides different medical services.

\subsection{Study Design and Population}

A cross-sectional facility-based study design was employed. All patients who visit the outpatient departments of Nekemte referral hospital were considered as source population whereas patients who received health care services at the outpatient department of the hospital during the study period, and who fulfilled the inclusion criteria were taken as the study population.

\subsection{Sample Size and Sampling Procedures}

The required sample size was determined by using a single population formula considering the following assumptions; the overall patient satisfaction with waiting time from previous study was $54.2 \%$ [10], level of significance $(\alpha / 2)$ $=0.05$ and marginal error $(\mathrm{d})=5 \% . \mathrm{n}=(\mathrm{Z} \alpha / 2)^{2} \mathrm{P} *(1-\mathrm{P}) / \mathrm{d}^{2}, \mathrm{n}=$ $(1.96)^{2} * 0.542(1-0.542)=382$ and adding $10 \%$ nonresponse rate, $\mathrm{n}=420$.

The participants were selected by using a systematic random sampling method and 420 respondents were taken for interview. The interval of the respondents for the interview was determined by dividing the average total number of patients per study period received health services at the outpatient department of the hospital by the required sample size for the study. Therefore, every $14^{\text {th }}(\mathrm{N} / \mathrm{n}=5924 / 420)$ patients were selected for the interview at the hospital from registration books and a simple random sampling technique was employed to select the first participant.

All patients attending the outpatient department of the hospital and willing to participate in this study were included in the study after taking consent and for a patient whose age was less than 15 years their caregivers were interviewed whereas patients working in the study hospital and patients with serious physical, mental pathologies and psychosis were excluded.

\subsection{Data Collection Tool and Method}

Data was collected by face-to-face (exit interview) using a structured questionnaire. The questionnaire was developed in English after reviewing relevant literature and translated into Afan Oromo (the local language) and retranslated back into English to ensure its consistency. The questionnaire was pre-tested by 21 patients that accounted for $5 \%$ of the total sample size before conducting the actual data collection. The questionnaire contained the sociodemographic characteristics and patients' satisfaction indicators towards the hospital outpatient department services waiting time.

\subsection{Study Variables}

Outpatient satisfaction with waiting time for health services was the dependent variable and the independent study variables were socio-demographic characteristics of the outpatients (age, gender, marital status, place of residence, educational status, occupation and income), and waiting time for (registration, visiting physician, laboratory, drugs and payment).

A five (5) points Likert's scale rating of very dissatisfied (1), dissatisfied (2), fairly satisfied (3), satisfied (4) and very satisfied (5) were employed to assess the satisfaction. Seven satisfaction indicators of outpatient hospital waiting time for health care services were selected and the participants interviewed for their satisfaction toward each selected indicators (reception process, registration time, visiting physician, laboratory, radiology, drugs, and payment) to rate their satisfaction. Finally, the mean score of satisfaction was used to categorize the satisfaction level into satisfied ( $\geq$ mean score) and dissatisfied ( $<$ mean score) for each satisfaction indicators and overall satisfaction.

The waiting times experienced by outpatients were categorized into waiting time for registration (the time of reporting at the registration counter until a waiting number is given), waiting time to see doctor (the time the patient received the waiting number until the patient was called into the doctor's room), waiting time for laboratory services (the time the patient received laboratory tests request until the patient received the laboratory results), waiting time for 
radiology (the time the patient received radiology tests request until the patient received the results), waiting time for drugs (the time the patient received the prescription till the patient received drugs), and waiting time for payment (the time the patient received the payment orders for services till the patient completed payments for services) [11] and the internal consistency was checked using cronbach's alpha coefficient and it was found to be 0.895 to ensure that the seven items identified as indicators for outpatient satisfaction with waiting time hospital health services provision.

\subsection{Data Management and Analysis}

The completed questionnaires were being checked for completeness, consistency and coded by the principal investigators and supervisors. After completeness of each questionnaire checked, data entry and analysis were made using SPSS for windows version 20 software.

Descriptive statistics of frequency was performed for all study variables. Simple logistic regression (bivariate analysis) was performed to identify association between each independent and dependent variables. All variables associated with outpatient satisfaction with waiting time in bivariate analysis were considered to be candidate variable with $p \leq 0.25$. Those candidate variables were entered into multivariable logistic regressions to identify predictors of outpatient satisfaction with waiting time at $\mathrm{p}<0.05$ to declare level of significance.

\subsection{Ethical Consideration}

The protocol of this study was approved by the Review Board of Nekemte Referral Hospital (Reference number (NRH/5012/08). We obtained the written informed consent of the participants before collecting any data and the objective of the research was explained to all subjects and also confidentiality was maintained.

\section{Results}

\subsection{Socio-demographic Characteristics}

From a total of 420 interviewed participants, 387 of them responded to the interview making $92.2 \%$ response rates. The majority of the study participants were male 248 (64.1\%) and from urban area $270(69.8 \%)$. Most of the respondents' age was in the age group 16-30 years and followed by $31-45$ years with $205(53 \%)$ and $122(31.5 \%)$ respectively.

More than half of the participants 230 (59.4\%) were married and their educational status was 183 (47.3\%) had diploma and above followed by elementary school 80 $(20.7 \%)$. Most of the average monthly income of respondents 107 (36.5\%) was between 150-600 Ethiopian Birr (ETB) and $73(24.9 \%)$ of respondents had monthly income of 12012500 ETB per month out of 293 respondents who gave a response on their monthly income (Table 1).

Table 1. Socio-demographic characteristics of outpatient visited Nekemte referral hospital Nekemte, Oromia National Regional State, Ethiopia.

\begin{tabular}{|c|c|c|c|c|}
\hline \multirow{2}{*}{\multicolumn{2}{|c|}{ Socio-demographic Characteristics }} & \multicolumn{3}{|c|}{ Satisfaction level } \\
\hline & & $\begin{array}{l}\text { Satisfied } \\
\mathrm{N}=201(\%)\end{array}$ & $\begin{array}{l}\text { Unsatisfied } \\
\mathrm{N}=186(\%) \\
\end{array}$ & $\begin{array}{l}\text { Total } \\
\mathrm{N}=\mathbf{3 8 7}(\%)\end{array}$ \\
\hline \multirow{3}{*}{ Sex } & & & & \\
\hline & Male & $149(67.4)$ & $99(59.6)$ & $221(64.1)$ \\
\hline & Female & $72(32.6)$ & $67(40.4)$ & $139(35.9)$ \\
\hline \multirow{3}{*}{ Age (years) } & $\leq 30$ & $111(54.1)$ & $94(45.9)$ & $205(53)$ \\
\hline & $31-45$ & $69(17.8)$ & $53(13.7)$ & $122(31.5)$ \\
\hline & $>45$ & $33(8.5)$ & $27(7)$ & $60(15.5)$ \\
\hline \multirow{3}{*}{ Marital status } & Single & $68(47.9)$ & $74(19.1)$ & $142(36.7)$ \\
\hline & Married & $126(32.6)$ & $104(26.9)$ & $230(59.4)$ \\
\hline & Divorced & $7(1.8)$ & $8(2.1)$ & $15(3.9)$ \\
\hline \multirow{2}{*}{ Place of Residence } & Urban & $138(35.7)$ & $132(34.1)$ & $270(69.8)$ \\
\hline & Rural & $54(14)$ & $63(16.3)$ & $117(30.2)$ \\
\hline \multirow{4}{*}{ Educational Status } & Illiterate & $37(9.6)$ & $15(3.9)$ & $52(13.4)$ \\
\hline & Elementary school & $43(11.1)$ & $37(9.6)$ & $80(20.7)$ \\
\hline & High school & $38(9.8)$ & $34(8.8)$ & $72(18.6)$ \\
\hline & Diploma and above & $83(21.4)$ & $100(25.8)$ & $183(47.3)$ \\
\hline \multirow{4}{*}{ Monthly Income (ETB) $(n=293)$} & $150-600$ & $64(21.8)$ & $43(14.7)$ & $107(36.5)$ \\
\hline & $601-1200$ & $25(8.5)$ & $22(7.5)$ & $47(16.0)$ \\
\hline & $1201-2500$ & $43(14.7)$ & $30(10.2)$ & 73 (24.9) \\
\hline & $>2501$ & $42(14.3)$ & $24(8.2)$ & $66(22.5)$ \\
\hline
\end{tabular}

\subsection{Waiting Time Condition at Different Units}

The waiting times of the outpatient series were assessed as waits for registration, visiting physicians, laboratory services, radiology services, prescribed drugs, and paying for services
(Table 2). Accordingly, waiting time for registration 165 $(42.6 \%)$ of patients waited for $>60$ minutes and only 102 $(26.4 \%)$ of the patients registered within 30 minutes. More than half of patients $214(55.3 \%)$ visited the doctor after waiting for $>60$ minutes and only $64(16.5 \%)$ of the patients 
visited their doctors within $\leq 30$ minutes.

Table 2. Waiting time conditions at Nekemte referral hospital outpatient departments, Oromia National Regional State, Ethiopia.

\begin{tabular}{|c|c|c|c|c|}
\hline \multirow{2}{*}{\multicolumn{2}{|c|}{ Waiting time for services at different units }} & \multicolumn{3}{|c|}{ Satisfaction level } \\
\hline & & \begin{tabular}{l|} 
Satisfied \\
N (\%) \\
\end{tabular} & \begin{tabular}{l|l} 
Unsatisfied \\
$\mathrm{N}(\%)$ \\
\end{tabular} & \begin{tabular}{l|} 
Total \\
N (\%) \\
\end{tabular} \\
\hline \multirow{3}{*}{ Waits for registration $(\mathrm{n}=387)$} & $<30 \mathrm{~min}$ & $69(178)$ & $33(85)$ & 102064 \\
\hline & $30-60 \mathrm{~min}$ & $71(18.3)$ & $49(12.7)$ & $120(31.0)$ \\
\hline & $>60 \mathrm{~min}$ & $81(20.9)$ & $84(21.7)$ & $165(42.6)$ \\
\hline \multirow{3}{*}{ Waits for physician visit ( $\mathrm{n}=387$ ) } & $\leq 30 \min$ & $48(12.4)$ & $16(4.1)$ & $64(16.5)$ \\
\hline & $30-60 \mathrm{~min}$ & $62(16.0)$ & $47(12.1)$ & $109(28.2)$ \\
\hline & $>60 \mathrm{~min}$ & $111(50.2)$ & $103(62.0)$ & $214(55.3)$ \\
\hline \multirow{3}{*}{ Waits for laboratory $(\mathrm{n}=365)$} & $\leq 30 \mathrm{~min}$ & $28(7.7)$ & $16(4.3)$ & $44(12.0)$ \\
\hline & $30-60 \mathrm{~min}$ & $128(35.1)$ & $84(23.0)$ & $212(58.1)$ \\
\hline & $>60 \mathrm{~min}$ & $54(14.8)$ & $55(15.1)$ & $109(29.9)$ \\
\hline \multirow{3}{*}{ Waits for radiology $(n=162)$} & $\leq 30 \mathrm{~min}$ & $22(13.6)$ & $3(1.9)$ & $25(15.4)$ \\
\hline & $30-60 \mathrm{~min}$ & $13(21.6)$ & $13(8.0)$ & $48(29.6)$ \\
\hline & $>60 \mathrm{~min}$ & $39(24.1)$ & $50(30.9)$ & $89(54.9)$ \\
\hline \multirow{3}{*}{ Waits for drugs at pharmacy $(n=377)$} & $\leq 30 \mathrm{~min}$ & $61(16.2)$ & $28(7.4)$ & $89(23.6)$ \\
\hline & $30-60 \mathrm{~min}$ & $85(22.5)$ & $60(15.9)$ & $145(38.5)$ \\
\hline & $>60 \mathrm{~min}$ & $68(18.0)$ & $75(19.9)$ & $143(37.9)$ \\
\hline \multirow{3}{*}{ Waits payment $(\mathrm{n}=378)$} & $\leq 30 \mathrm{~min}$ & $57(26.1)$ & $22(5.8)$ & 79 (20.9) \\
\hline & $30-60 \mathrm{~min}$ & $100(26.5)$ & $96(25.4)$ & $196(51.9)$ \\
\hline & $>60 \mathrm{~min}$ & $61(16.1)$ & $42(11.1)$ & $103(27.2)$ \\
\hline
\end{tabular}

From a total of 365 patients who had laboratory test requests, $212(58.1 \%)$ of them obtained the services within 30-60 minutes and only $44(12.0 \%)$ of them obtained the services within $\leq 30$ minutes. Out of 162 patients who had radiology requests (x-ray or ultrasound), more than half them $89(54.9 \%)$ waited for $>60$ to get the services and only $25(15.4 \%)$ obtained the services within $\leq 30$ minutes.

Regarding the waiting time to obtain drugs, from a total of 377 patients who had prescribed drugs, only 89 (23.6\%) of them obtained the prescribed drugs within $\leq 30$ minutes and the number of patients who obtained the drugs within 30-60 minutes and $>60$ minutes from the outpatient pharmacy were almost the same which were 145 (38.5\%) and 143 (37.9\%) respectively.

From a total of 378 patients who paid for the services, more than half them $196(51.9 \%)$ obtained the services within 30-60 minutes and only 79 (20.9\%) obtained the services within $\leq 30$ minutes.

The participants were also interviewed to comment on the reasons that they perceived that prolonged their waiting time and from a total of 387 participants responded to the interview, $319(82.4 \%)$ of the patients reasoned out different reasons that prolonged their waiting time after their arrival of the hospital. According to them, 119 (37.3\%) of them commented that there was no directional sign and number of rooms were not well labeled with their services, 85 (26.6\%) patients were too many during their outpatients visits, 50 $(15.7 \%)$ the number of physicians was few to visit all patients timely, 45 (14.1\%) few record clerks on desk, and 20
$(6.3 \%)$ shunting by other patients.

\subsection{Outpatient Satisfaction with Waiting Time}

The overall satisfaction of patients with waiting time for outpatient hospital services at Nekemte referral hospital was $221(57.1 \%)$ (Figure 1).

Overall satisfaction level with waiting time among outpatients

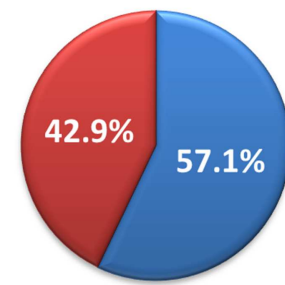

- Satisfied

Dissatisfied

Figure 1. Level of overall satisfaction of outpatients with waiting time at Nekemte Referral hospital, Oromia National Regional State, Ethiopia.

From a total of 387 participants, only 93 (24\%) were satisfied with the reception process and $122(31.5 \%)$ were satisfied with the waited time for registration whereas only $153(39.5 \%)$ were satisfied with the time they spent to visit their physicians.

Majority of the patients, $232(63.6 \%)$ were satisfied with waiting time to obtain the requested laboratory tests whereas only $77(47.5 \%)$ of the patients were satisfied with the waiting time they spent to get radiology services from a total of 365 and 162 patients who had laboratoryy and radiology requests respectively. Out of 377 of patients who had drugs prescription, 
more than half of them 209 (55.4\%) were satisfied with the time they spent to obtain drugs from the hospital and from a total of 378 of outpatients who paid for the health care services they received, majority of them $245(64.8 \%)$ were satisfied with the time they waited for the payment (Table 3 ).

Table 3. Level of satisfaction of patients with waiting time at outpatient departments in Nekemte referral hospital, Oromia National Regional State, Ethiopia.

\begin{tabular}{|c|c|c|c|c|c|c|}
\hline Variables & $\begin{array}{l}\text { Very dissatisfied } \\
(\%)\end{array}$ & Dissatisfied (\%) & $\begin{array}{l}\text { Fairly satisfied } \\
(\%)\end{array}$ & Satisfied (\%) & $\begin{array}{l}\text { Very satisfied } \\
(\%)\end{array}$ & $\begin{array}{l}\text { Satisfied* } \\
(\%)\end{array}$ \\
\hline Reception proces $(\mathrm{n}=387)$ & $41(10.6)$ & $74(19.1)$ & $144(37.2)$ & $94(24.3)$ & $34(8.8)$ & $93(24)$ \\
\hline Waits fo Registaration $(\mathrm{n}=387)$ & $38(9.8)$ & $65(16.8)$ & $162(41.1)$ & $101(26.1)$ & $21(5.4)$ & $122(31.5)$ \\
\hline Waits to visit physician $(n=387)$ & $23(5.9)$ & $83(21.4)$ & $128(33.1)$ & $107(27.6)$ & $43(11.9)$ & $153(39.5)$ \\
\hline Waits for $\mathrm{Lab}(\mathrm{n}=365)$ & $43(11.8)$ & $90(24.7)$ & $141(38.6)$ & $64(17.5)$ & $27(7.4)$ & $232(63.6)$ \\
\hline Waits for radiology $(n=162)$ & $3(1.9)$ & $29(17.9)$ & $53(32.7)$ & $51(3.5)$ & $26(16)$ & $77(47.5)$ \\
\hline Waits for drugs $(\mathrm{n}=377)$ & $16(4.1)$ & $42(10.9)$ & $110(28.4)$ & $161(41.6)$ & $48(12.4)$ & $209(55.4)$ \\
\hline Overall satisfaction & & & & & & $221(57.1)$ \\
\hline
\end{tabular}

*-Classified by using a mean score of that specific indicator as a demarcation threshold

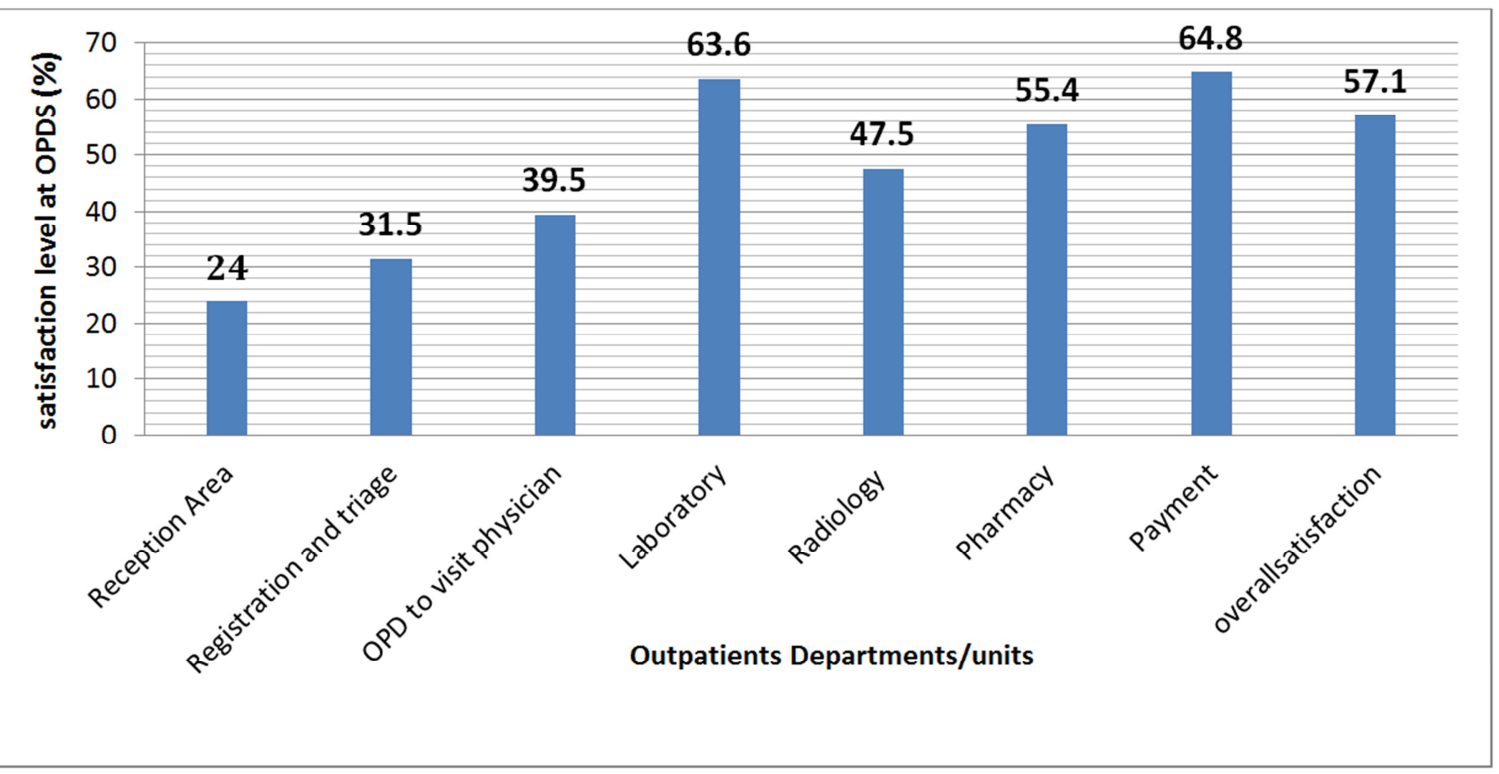

Figure 2. Outpatient satisfaction level with waiting time at Nekemte referral hospital outpatient departments, Oromia National Regional State, Ethiopia.

\subsection{Predictors of Outpatient Satisfaction with Waiting Time}

To identify the predictors of outpatient satisfaction with waiting time to receive health care at the hospital outpatient departments; multiple logistic regression analysis was performed. Accordingly, none of the socio-demographic characteristics of the patients was significantly associated with outpatients' overall satisfaction with waiting time for health services at the hospital (Table 4).

Those outpatients who obtained registration services within $\leq 30$ minutes were almost two times more likely satisfied with waiting time than those patients who spent $>60$ minutes to obtain the services [AOR of $95 \% \mathrm{CI}=1.94(1.07-$ 3.5)]. After their registration, those patients who waited for their physicians to visit for $\leq 30$ minutes were 2.4 more likely satisfied with waiting time compared to those patients who visited a physician after waiting for $>60$ minutes [AOR of 95\% CI=2.38 (1.18-4.81)].

The outpatients who obtained laboratory services within 30-60 minutes were almost two times more likely satisfied with outpatient waiting time than those patients who obtained laboratory services after waiting for $>60$ minutes [AOR of $95 \% \mathrm{CI}=1.79(1.07-3.01)]$.

Table 4. Predictors of outpatient satisfaction with waiting time at Nekemte Referral hospital, Oromia National Regional State, western Ethiopia.

\begin{tabular}{llll}
\hline \multirow{2}{*}{ Variables } & Satisfaction Level & & Odds Ratio and 95\% CI \\
\cline { 2 - 4 } & Satisfied (\%) & Dissatisfied (\%) & Crude odds ratio (COR) \\
\hline Sex (n=387) & 221 & 166 & \\
Male & $149(67.4)$ & $99(59.6)$ & $1.401(0.921-2.129)$ \\
Female & $72(32.6)$ & $67(40.4)$ & 1 \\
Marital Status (n=387) & 201 & 186 & \\
Single & $68(47.9)$ & $74(19.1)$ & $1.777(0601-5.256)$ \\
Married & $126(32.6)$ & $104(26.9)$ & $2.250(0.775-6.534)$ \\
Divorced & $7(1.8)$ & $8(2.1)$ & 1 \\
\hline
\end{tabular}




\begin{tabular}{|c|c|c|c|c|}
\hline \multirow{2}{*}{ Variables } & \multicolumn{2}{|c|}{ Satisfaction Level } & \multicolumn{2}{|l|}{ Odds Ratio and $95 \%$ CI } \\
\hline & Satisfied (\%) & Dissatisfied (\%) & Crude odds ratio (COR) & Adjusted odds ratio (AOR) \\
\hline Educational status $(\mathrm{n}=387)$ & 201 & 186 & & \\
\hline Illiterate & $37(9.6)$ & $15(3.9)$ & $2.047(1.051-3.988)$ & $2.362(1.106-5.043)$ \\
\hline Elementary & $43(11.1)$ & $37(9.6)$ & $0.965(0.569-1.634)$ & $1.146(0.621-2.116)$ \\
\hline High school & $38(9.8)$ & $34(8.8)$ & $1.098(0.633-1.902)$ & $1.245(.650-2.384)$ \\
\hline Diploma and above & $83(21.4)$ & $100(25.8)$ & 1 & 1 \\
\hline Waits for Registration $(\mathrm{n}=387$ ) & 221 & 166 & & \\
\hline $30-60 \mathrm{~min}$ & $71(18.3)$ & $49(12.7)$ & $1.503(0.934-2.416)$ & $1.396(0.785-2.483)$ \\
\hline$>60 \mathrm{~min}$ & $81(20.9)$ & $84(21.7)$ & 1 & 1 \\
\hline Waits for physician $(n=387)$ & 221 & 166 & & \\
\hline$\leq 30 \mathrm{~min}$ & $48(12.4)$ & $16(4.1)$ & $2.784(1.488-5.207)$ & $2.378(1.176-4.809)^{*}$ \\
\hline $30-60 \mathrm{~min}$ & $62(16.0)$ & $47(12.1)$ & $1.224(0.769-1.947)$ & $1.042(0.596) 1.822)$ \\
\hline$>60 \min$ & $111(50.2)$ & $103(62.0)$ & 1 & 1 \\
\hline Waits for laboratory $(n=365)$ & 210 & 155 & & \\
\hline $30-60 \mathrm{~min}$ & $128(35.1)$ & $84(23.0)$ & $1.552(0.974-2.472)$ & $1.793(1.068-3.010)^{*}$ \\
\hline$>60 \min$ & $54(14.8)$ & $55(15.1)$ & 1 & 1 \\
\hline Waits for drugs $(\mathrm{n}=377)$ & 214 & 163 & & \\
\hline$\leq 30 \min$ & $61(16.2)$ & $28(7.4)$ & $2.403(1.380-4.185)$ & $3.087(1.646-5.788)^{* * *}$ \\
\hline $30-60 \mathrm{~min}$ & $85(22.5)$ & $60(15.9)$ & $1.562(0.981-2.489)$ & $1.50(0.894-2.518)$ \\
\hline$>60 \mathrm{~min}$ & $68(18.0)$ & $75(19.9)$ & 1 & 1 \\
\hline Waits for payment $(n=378)$ & 218 & 168 & & \\
\hline$\leq 30 \mathrm{~min}$ & $57(26.1)$ & $22(5.8)$ & $1.784(0.950-3.348)$ & $2.024(1.032-3.970)^{*}$ \\
\hline $30-60 \mathrm{~min}$ & $100(26.5)$ & $96(25.4)$ & $0.717(0.443-1.162)$ & $0.706(0.413-1.208)$ \\
\hline$>60 \mathrm{~min}$ & $61(16.1)$ & $42(11.1)$ & 1 & 1 \\
\hline
\end{tabular}

Notes: ${ }^{*} \mathrm{P}$-value $<0.05,{ }^{*} \mathrm{P}$-value $<0.01, * * * \mathrm{P}$-value $<0.001$ and $1=$ reference, $\mathrm{CI}=$ Confidence Interval, min $=$ minutes

The patients who received the prescribed drugs from the pharmacy of the hospital within $\leq 30$ minutes were three times more likely satisfied with outpatient waiting time compared to those patients who obtained the prescribed drugs after waiting for $>60$ minutes [AOR of $95 \% \mathrm{CI}=3.09$ (1.655.79)] and those patients who paid for the services within $\leq 30$ were two times more likely satisfied than those patients who paid for the services after waiting for $>60$ minutes [AOR of $95 \% \mathrm{CI}=2.02(1.03-3.97)]$.

\section{Discussion}

The study finding has revealed, the overall satisfaction of outpatients with waiting time was $57.1 \%$ which was almost similar to the report of the study at Wolayita Sodo hospital in Ethiopia 54.2\% [10]. But, it was higher than the study finding in Tigray, Ethiopia 44\% [12], however, lower than the study report from Nigeria which showed that patients' satisfaction with waiting area was $77 \%$ [13].

There was no significant association between outpatient satisfaction with waiting time and the socio-demographic characteristics of the patients. Similarly, the study report in Malaysia revealed that there was no significant association between patient satisfaction toward waiting time and patients' socio-demographic profile [11].

The outpatient satisfaction with waiting time for registration was $31.5 \%$ which was relatively low compared to satisfaction level with waiting time reported in Nigeria $45 \%$ and those patients who waited for $\leq 30$ minutes were almost two more likely satisfied with outpatient waiting time compared to those patients who waited for $>60$ minutes. Similarly, the study conducted in Nigeria showed that the patients who waited for $\geq 60$ minutes for registration were significantly dissatisfied with the health services [14].

According to the study, only $26.4 \%$ of patients registered within 30 minutes which was low compared to the study report in India $50 \%$ of outpatients obtained registration within 20 minutes [15]. This difference might be due to the patient flow, numbers of staffs and the technology used for registration of patients may vary at these two different study hospitals.

The study also revealed that the satisfaction level of patients with waiting time to see doctors was $39.5 \%$ which was lower than study finding in Nigeria $71 \%$ [13]. It showed that those patients who waited to see physician for $\leq 30$ minutes were 2.4 more likely satisfied than those patients who waited for physician visiting for $>60$ minutes which was in line with the study report at Wolayita Sodo hospital in Ethiopia that showed those patients who waited for $\leq 30 \mathrm{~min}$ were 3 times more likely satisfied with waiting time compared to those who waited for $>60$ minutes [10].

The study also revealed that majority of the patients $63.6 \%$ were satisfied with waiting time for laboratory which was almost similar to the study finding at Nekemte referral hospital laboratory in Ethiopia which was $68.2 \%$ of the patients were satisfied waiting time for laboratory services [16], but, higher than the study report in Nigeria 47.2\% [13].

The laboratory waiting time was significantly associated with outpatient satisfaction with waiting time that showed those patients who obtained laboratory services between 3060 minutes were almost two times more likely satisfied with waiting time compared to those patients who spent $>60$ minutes to obtain laboratory services. But, it was contrasting to study report conducted in Ethiopia at Shanen Gibe hospital 
which revealed that patients who waited for laboratory services $\leq 30 \mathrm{~min}$ and 60-120 minutes were more like satisfied than those patients waited for $>120$ minutes [17]. The variation could be due to the patient flow and laboratory level variation between the study hospitals.

The outpatient satisfaction level with waiting time for drugs at the hospital pharmacy was $55.4 \%$ and similar to patient waiting time for drugs at Gondar University hospital in Ethiopia 53.1\% [18]. But, it was lower than the study report in Nigeria $75.4 \%$ [13] and in Tanzania, $76.3 \%$ of patients were satisfied with pharmacy waiting time [19].

At most outpatient departments, those patients who waited for services for only $\leq 30$ minutes were more likely satisfied when compared to those patients waited for $>60$ minutes. Similarly, the study finding in Saudi Arabia revealed that the only factor that had a significant influence on overall satisfaction was waiting time, with those waiting for $>30$ minutes reported that they were dissatisfied with health services provided in the health care facilities [20] and reducing the waiting time for health care may lead to improved patient satisfaction [21].

Generally, the study findings variation could be due to the patients flow, the physical structure of the study facilities, the distance between units in hospitals, the number of manpower, the day of visits, technology and time variation at those different study health facilities of different countries.

The study evaluated waiting time for health services at different outpatient departments of the hospital by directly interviewing the patients and recall bias may be there on waiting time to get services from the hospital.

\section{Conclusion}

The overall outpatient satisfaction with waiting time to receive health services at the outpatient department of Nekemte referral hospital was relatively low compared to other many study findings. At most outpatient departments, those patients who waited for services for $\leq 30$ minutes were more likely satisfied than those patients who waited for services for $>60$ minutes. The significant factors of this satisfaction were the waiting time the outpatient spent to get registration, see physician, pay for services, obtain laboratory services, and prescribed drugs.

Accordingly, we recommend the hospital to reduce the waiting time for registration, visiting physician, drugs and payment to $\leq 30$ minutes and the waiting time for laboratory services to $<60$ minutes to increase outpatient satisfaction with waiting time and further study is recommended on how to reduce the waiting time at outpatient departments of the hospital in future.

\section{Acknowledgements}

We are grateful to the study participants and our special thanks go to administrative and medical staffs at Nekemte referral hospital for their invaluable information and support of this study.

\section{Competing Interests}

The authors declare no conflict of interest. This study received no external funding.

\section{References}

[1] Vinagre MH, Neves J. The Influence of Service Quality and Patients' Emotions on Satisfaction. International Journal of Health Care Quality Assurance. Int J Health Care Qual Assur. 2008; 21 (1): 87-103: DOI: 10.1108/09526860810841183.

[2] Silva AD. A framework for ensuring responsiveness. GPE discussion paper series: No. 32. World Health Organization.

[3] Girma M. Assessment of inpatients' satisfaction on quality of care and associated factors at Zewditu memorial hospital, Addis Ababa, $2015 . \quad$ Available at: www.etd.aau.edu.et/bitstream/123456789/7575/1/Mahlet $\% 20$ Girma.pdf

[4] Fatma PM, Mursyid HB, The Analysis of Appointment System to Reduce Outpatient Waiting Time at Indonesia's Public Hospital, Human Resource Management Research. 2013; 3 (1): 27-33. Doi: 10.5923/j.hrmr.20130301.06.

[5] Claudia A. Toward Standard Definitions for Waiting Times. Steering Committee of the Western Canada Waiting List Project. 2003; 16 (2): 49-59.

[6] Anil P, Lalit V, Amruta P. Impact of OPD waiting time on patient satisfaction. International Education and Research journal [IERJ]. 2016; 2 (8): 86-90.

[7] Jawaha, SK. A study on outpatient satisfaction at a super specialty hospital in India. Internet Journal of Medical Update. 2 (2): 2007; 11-15.

[8] Clifford B, David B. Rothschild, BS; Andrew V, Eduardas V, Laura S, etal. Wait Times, Patient Satisfaction Scores, and the Perception of Care. Am J Manag Care. 2014; 20 (5): 393-400.

[9] Bahrampour A, Zolala F. Patient satisfaction and related factors in Kerman hospitals. EMHJ - Eastern Mediterranean Health Journal. 2005; 11 (5-6): 905-912.

[10] Getu GS, Alemayehu WY, Mengistu MK. Patients' Satisfaction and Associated Factors Among Outpatient Department at Wolaita Sodo University Teaching Hospital, Southern Ethiopia: A Cross Sectional Study. Science Journal of Clinical Medicine. 2015; 4 (5): 109-116. Doi: 10.11648/j.sjcm.20150405.16.

[11] Raja Lexshimi RG, and Zaleha MI, and Shamsul AS, and Suriawati G. Patient satisfaction on waiting time and duration of consultation at Orthopedic Clinic, Universiti Kebangsaan Malaysia Medical Centre. Medicine \& Health. 2009; 4 (1): 3546.

[12] Girmay A, Getinet M. Assessment of clients' satisfaction with outpatient services in Tigray Zonal Hospitals, 2014; Available at: http://www.ncbi.nlm.nih.gov/pmc/articles/PMC3275861

[13] Daprim SO, Margaret MO Mezie-Okoye. Waiting time and patient satisfaction: Survey of patients seeking care at the general outpatient clinic of the University of Port Harcourt Teaching Hospital, Nigeria; 2015. DOI: 10.4103/phmj.phmj_41_17. 
[14] Oche U, Umar AS. Patient waiting time in a tertiary health institution in Northern Nigeria. J Public Health Epidemiology. 2011; 3 (2): 78-82.

[15] Ravikant P, Hinaben R. A study on waiting time and outpatient satisfaction at Gujarat medical education research society hospital, Valsad, Gujarat, India. International Journal of Community Medicine and Public Health Patel R et al. Int J Community Med Public Health. 2017; 4 (3): 857-863.

[16] Geletta T, Eyasu E, Mikias D, Shibabew A, Keneni E. Patients Satisfaction on Clinical Laboratory Services at Nekemte Referral Hospital, Oromia, Ethiopia. Food Science and Quality Management. 2014; Vol. 30.

[17] Melal T, Shiferaw B. Assessment of Patients' Satisfaction Towards General Medical Laboratory Services at Shenen Gibe Public Hospital, Jimma Town, South West Ethiopi. Journal of
Health, Medicine and Nursing. 2016; Vol. 31.

[18] Ayalew MB, Taye K, Asfaw D, et al. Patients'/Clients' Expectation Toward and Satisfaction from Pharmacy Services. J Res Pharm Pract. 2017; 6 (1): 21-26. Doi: 10.4103/2279042X.200995.

[19] M. Jande, A. Liwa, G. Kongola, M. Justin. Assessment of Patient Satisfaction with Pharmaceutical Services in Hospital Pharmacies in Dares Salaam, Tanzania. East Cent. Afr. J. Pharm.

[20] Med F, Sci M, Alnemer KA, et al. A multicenter study of factors affecting patient's satisfaction visiting primary health care clinics in Riyadh, Saudi Arabia. Fam Med Med Sci Res. 2015; 4: 2-5.

[21] Camacho F, Anderson R, Safrit A, Jones AS, Hoffmann P. The relationship between patients's perceived waiting time and office-based practice satisfaction. N C Med J 2006; 67: 409-13. 